\title{
Psychological reflection of cultural diversity: older Muslim and Jewish women diagnosed with cancer or caring for a spouse with cancer
}

\section{Y. Rottenberg ( $\nabla$ ryakir@hadassah.org.il)}

Hadassah Medical Organization and Faculty of Medicine, Hebrew University of Jerusalem

\section{Baider}

Assuta Medical Center

J. M. Jacobs

Hadassah Medical Organization and Faculty of Medicine, Hebrew University of Jerusalem

I. M. Ghrayeb

Makassed Hospital, East Jerusalem

E. Sapir

Samson Assuta Hospital

G. Goldzweig

Tel-Aviv-Yaffo Academic College

\section{Research Article}

Keywords: cancer, caregivers, women, Muslim, Jews, cultural diversity

Posted Date: February 21 st, 2022

DOI: https://doi.org/10.21203/rs.3.rs-1275611/v1

License: () (1) This work is licensed under a Creative Commons Attribution 4.0 International License.

Read Full License 


\section{Abstract \\ BACKGROUND}

As the global population continues to age, the number of women aged $65+$ diagnosed with cancer, or caring for a spouse with cancer, continues to increase. The psychological response to cancer among this growing population of patients and informal caregivers has been poorly researched in general, and psycho-oncology literature among older Muslim women research is particularly sparse. This study examines and compares the relationship between depression, hope and perceived support among older Muslim Palestinian and Jewish Israeli women either diagnosed with cancer or informal caregivers of spouses with cancer.

\section{METHODS}

A cross-sectional study of a convenience sample of Muslim Palestinian women (91 patients, 61 spousal caregivers) and Jewish Israelis (127 patients, 214 spousal caregivers) women. Patients were aged $\geq 65$, either receiving treatment for active disease or $<6$ months from diagnosis. Measurements included depression (Geriatric Depression Scale, 5-item), hope (Snyder's Adult Hope Scale) and perceived social support (Cancer Perceived Agents of Social Support of social support questionnaire).

\section{RESULTS}

Overall levels of depression measured among the Muslim Palestinian women were significantly higher than among Jewish Israelis $(p<0.0001)$. For the Jewish Israelis, higher levels of depression were found among patients compared to caregivers (interaction effect role $X$ ethnicity $p<0.0001$ ). Overall levels of hope among Muslims were higher compared to Jewish Israelis $(p<0.0001)$, being similar for both patients and caregivers (non significant role effect $p=0.094$ ). Hope was higher among Jewish caregivers vs. patients (interaction effect role $X$ ethnicity $p<0.021$ ). Despite a higher number of household members, levels of perceived support from spouse, family, as well as friends and faith, were lower among Muslim Palestinian in general, most significantly among caregivers.

\section{CONCLUSIONS}

We observed significant differences in depression, hope and perceived support amaong groups. Our findings highlight the different psychological responses among older women from different cultural landscapes facing similar confrontation with cancer, either as patients or spousal caregivers. Cultural sensitivity is imperative to guide possible interventions aimed at ameliorating the impact of cancer care upon older women. 


\section{Introduction}

Cancer is a leading cause of death among women across the world, respectively ranking as the second, third, fourth and six leading cause of mortality in the Western Pacific, Eastern Mediterranean, Southeast Asia, and Africa [1]. In 2012, the WHO's International Agency for Research on Cancer (IARC) reported 6.7 million new cancer cases and 3.5 million cancer deaths among women worldwide (53 percent of cases and 64 percent of deaths in non-Western countries). Demographic trends in population growth, driven in particular by global aging, predict that by 2030 there will be 9.9 million cancer cases and 5.5 million deaths annually [2]. In order to address and ameliorate the global burden of cancer illness among the growing number of older women, age and gender-specific aspects of its care must be identified, and gender inequalities confronted [2-5].

Each society has its own distinct characteristics and particular family culture, which frame attitudes toward women's roles, concepts of health and suffering, decisions about life, illness, death, beliefs and a critical range of opinions. Nor are these belief systems and cultural constructs static. They form a tapestry of responses and implicit questions, such that similar stressors under different social and familial conditions may elicit diverse sets of emotional behaviors [6]. Confronted with the challenges of cancer, women try to make sense of their disease through constructed meanings, connotations and attributions, which may significantly influence their health practices, ranging from prevention, early diagnosis, treatment choices and compliance. Because cancer affects not only the individual, attempts to make sense of it and choose healthcare practices and behaviors are inevitably pervaded by the sociocultural milieu $[7,8]$.

Disparities exist within the psycho-oncology literature among women in general, and older women in particular, with the majority of literature emerging from Western countries. Thus for example, the lack of psycho-oncology research among Muslim majority countries has recently been highlighted, in comparison to Western countries [9] Furthermore, among Muslim-minority countries, culturally specific psycho oncological considerations remain poorly integrated in oncology care in general, and particularly so among older women.

In order to address these issues, albeit at a local "micro-level", the current research setting is uniquely situated to contrast and compare certain psychological aspects associated with cancer diagnosis and caregiving for cancer patients among women with distinct cultural differences, who live in close geographical proximity - Muslim Palestinians and Jewish Israelis. Our study explores the psycho-cultural landscape of two groups of older women from each community, cancer patients and cancer caregivers. It compares psychological responses to cancer between older Jewish Israeli and Muslim Palestinian women themselves diagnosed with cancer, as well as between Jewish Israeli and Muslim Palestinian women who are primary informal caregivers to husbands with cancer. Specifically, it tries to understand the relationship between depression, hope and perceived support among Muslim and Jewish Israeli women patients and caregivers. Our hypothesis was that, because of their close-knit, extended cultural 
background, the older Muslim Palestinian women would experience different levels of depression, hope and perceived support.

\section{Methods}

\section{Inclusion and exclusion criteria}

The study population is part of an ongoing cross-sectional study on distress, social support and hope among patients aged $\geq 65$ years diagnosed with cancer and their informal caregivers and has been described earlier $[10,11,12]$. The current groups comprise a subsample of women from this study Muslim Palestinians and Jewish Israelis diagnosed with cancer and informal spousal caregivers to men with cancer.

INCLUSION CRITERIA FOR PATIENTS were a diagnosis of cancer at age $>=65$ years, and either currently in treatment for active disease or having concluded a course of treatment within six months of the enrolment date. Patients with non-metastatic cancer who were $>2$ years following diagnosis were considered survivors and not included in the study. Women designated by husbands with cancer as their primary caregiver for at least 10 years were enrolled.

PATIENTS WERE EXCLUDED if they were (1) receiving solely palliative care, (2) resident in a long-term care facility, (3) had impaired physical functioning (unable to use the lavatory without help), and (4) had major cognitive impairment (as determined by an overall global assessment by the study physicians).

INCLUSION CRITERIA FOR CAREGIVERS: spousal caregivers were recruited via the patients. They were required to have lived for at least 10 years with patients who were $\geq 65$ years old and diagnosed with cancer. CAREGIVERS WERE EXCLUDED if they themselves had (1) been diagnosed with a terminal illness, (2) been treated for cancer, or (3) had serious cognitive impairment (as determined by an overall global assessment by the study physicians).

\section{Recruitment sample}

MUSLIM PALESTINIAN GROUP: Muslim Palestinian patients were recruited through the outpatient oncology clinic of the Makassed Hospital in East Jerusalem, which provides tertiary care to the Palestinian population of East Jerusalem, the West Bank and Gaza Strip. The initial sample comprised 206 patient-caregiver dyads. Three caregivers refused to give informed consent, and one patient failed to meet the active disease criterion. In the remaining 202 dyads, 94 of the patients were women, of whom three did not complete all measures. The final Muslim Palestinian patient sample was thus 91 women with cancer. Of the 202 caregivers, 63 were wives of the patients they cared for. Two did not complete all measures, giving a final Muslim Palestinian spousal caregiver sample of 61 .

JEWISH ISRAELI GROUP: Jewish Israeli patients were recruited through the outpatient clinics of three major cancer centers in Israel. They initially comprised 428 patient-spousal caregiver dyads, of whom 34 refused to participate and 44 more were excluded because the patients were not in active treatment. Of 
the remaining 350 dyads, 130 patients were women and 220 were caregiver-wives. Three patients and six caregivers failed to complete all measures, producing a final sample of 127 Jewish Israeli women patients and 214 Jewish Israeli women spousal caregivers.

SAMPLE CHARACTERISTICS: Table 1 shows the sociodemographic and medical data of the 91 Muslim Palestinian patients, 61 Muslim Palestinian caregivers, 127 Jewish Israeli patients and 214 Jewish Israeli caregivers by group. The mean age of the patients was significantly higher than that of the caregivers (73.32 and 75.58 years, respectively, for Muslim Palestinian and Jewish Israeli patients vs. 65.02 and 70.07 years, respectively, for Muslim and Jewish caregivers). The Muslim Palestinians, both patients and caregivers, were significantly younger than the Jewish Israeli participants. The mean number of people per household was 3.8 for Muslim Palestinians, significantly higher than that in the Jewish Israeli households, which was around 2. Almost all the Jewish Israelis had high school education or beyond, significantly higher than the Muslim Palestinians. All but two of the Muslim Palestinian patients and their caregivers declared themselves religious or traditional. 
Table 1

Women's sociodemographic and medical data by study groups.

\begin{tabular}{|c|c|c|c|c|c|c|c|}
\hline & \multicolumn{2}{|c|}{ Muslims } & \multicolumn{2}{|l|}{ Jews } & \multicolumn{3}{|c|}{$\begin{array}{l}\text { Differences between the study } \\
\text { groups }\end{array}$} \\
\hline & Patient & Caregivers & Patient & Caregivers & Ethnicity & Role & Interactior \\
\hline & $N=91$ & $N=61$ & $\begin{array}{l}N= \\
127\end{array}$ & $N=214$ & & & \\
\hline \multirow{2}{*}{$\begin{array}{l}\text { Age (years) } \\
\text { mean } \pm S D \\
\text { range }\end{array}$} & $\begin{array}{l}73.32 \\
\pm 7.11\end{array}$ & $\begin{array}{l}65.02 \pm \\
7.86\end{array}$ & $\begin{array}{l}75.58 \\
\pm 9.09\end{array}$ & $\begin{array}{l}70.07 \pm \\
7.86\end{array}$ & $\begin{array}{l}F(1,489) \\
=21.00,\end{array}$ & $\begin{array}{l}F(1,489) \\
=74.83,\end{array}$ & $\begin{array}{l}F(1,489)= \\
3.08\end{array}$ \\
\hline & $65-92$ & $48-84$ & $65-95$ & $47-91$ & $\begin{array}{l}\mathrm{P}< \\
0.0001 * *\end{array}$ & $\begin{array}{l}\mathrm{P}< \\
0.0001 * *\end{array}$ & $\begin{array}{l}P<0.081 \\
\text { N.S }\end{array}$ \\
\hline \multirow{2}{*}{$\begin{array}{l}\text { Number of } \\
\text { persons in } \\
\text { household } \\
\text { mean } \pm \text { SD } \\
\text { range }\end{array}$} & $\begin{array}{l}3.80 \pm \\
2.46\end{array}$ & $\begin{array}{l}3.80 \pm \\
2.19\end{array}$ & $\begin{array}{l}2.35 \pm \\
0.92\end{array}$ & $\begin{array}{l}2.28 \pm \\
0.84\end{array}$ & $\begin{array}{l}F(1,483) \\
=97.96,\end{array}$ & $\begin{array}{l}F(1,483) \\
=0.44\end{array}$ & $\begin{array}{l}F(1,483)= \\
0.058\end{array}$ \\
\hline & $1-16$ & $2-9$ & $1-8$ & $1-8$ & $\begin{array}{l}P< \\
0.0001^{* *}\end{array}$ & $\begin{array}{l}\mathrm{P}<0.83 \\
\text { N.S }\end{array}$ & $\begin{array}{l}\mathrm{P}<0.81 \\
\text { N.S }\end{array}$ \\
\hline $\begin{array}{l}\text { Religiosity: } \\
\text { traditional } \\
\text { or religious }\end{array}$ & $\begin{array}{l}91 \\
(100 \%)\end{array}$ & 59 (97\%) & $\begin{array}{l}70 \\
(55 \%)\end{array}$ & $99(46 \%)$ & - & - & - \\
\hline \multirow[t]{2}{*}{$\begin{array}{l}\text { Education: } \\
\text { >=8 year } \mathrm{n} \\
(\%)\end{array}$} & $\begin{array}{l}24 \\
(26 \%(\end{array}$ & $31(51 \%)$ & $\begin{array}{l}107 \\
(84 \%)\end{array}$ & 197 (92\%) & $\begin{array}{l}\text { Odds } \\
\text { ratio }= \\
0.077\end{array}$ & $\begin{array}{l}\text { Odds } \\
\text { ratio }= \\
0.40\end{array}$ & $\begin{array}{l}\text { Odds } \\
\text { ratio = } \\
0.75\end{array}$ \\
\hline & & & & & $\begin{array}{l}\mathrm{P}< \\
0.0001^{* *}\end{array}$ & $\begin{array}{l}\mathrm{P}< \\
0.0001^{* *}\end{array}$ & $\begin{array}{l}\mathrm{P}<0.56 \\
\text { N.S }\end{array}$ \\
\hline
\end{tabular}

${ }^{*} \mathrm{p}<0.05$; ${ }^{*} \mathrm{p}<0.01$; Statistical significance was not calculated for religiosity since almost all Muslims declared to be religious or traditional ECOG = The Eastern Cooperative Oncology Group performance status ( 0 = fully active; $1=$ symptomatic but completely ambulatory; $2=$ symptomatic, $<50 \%$ in bed during the day; 3 = symptomatic, capable of only limited self-care); $\mathrm{CCl}=$ Charlson Comorbidity Index. 


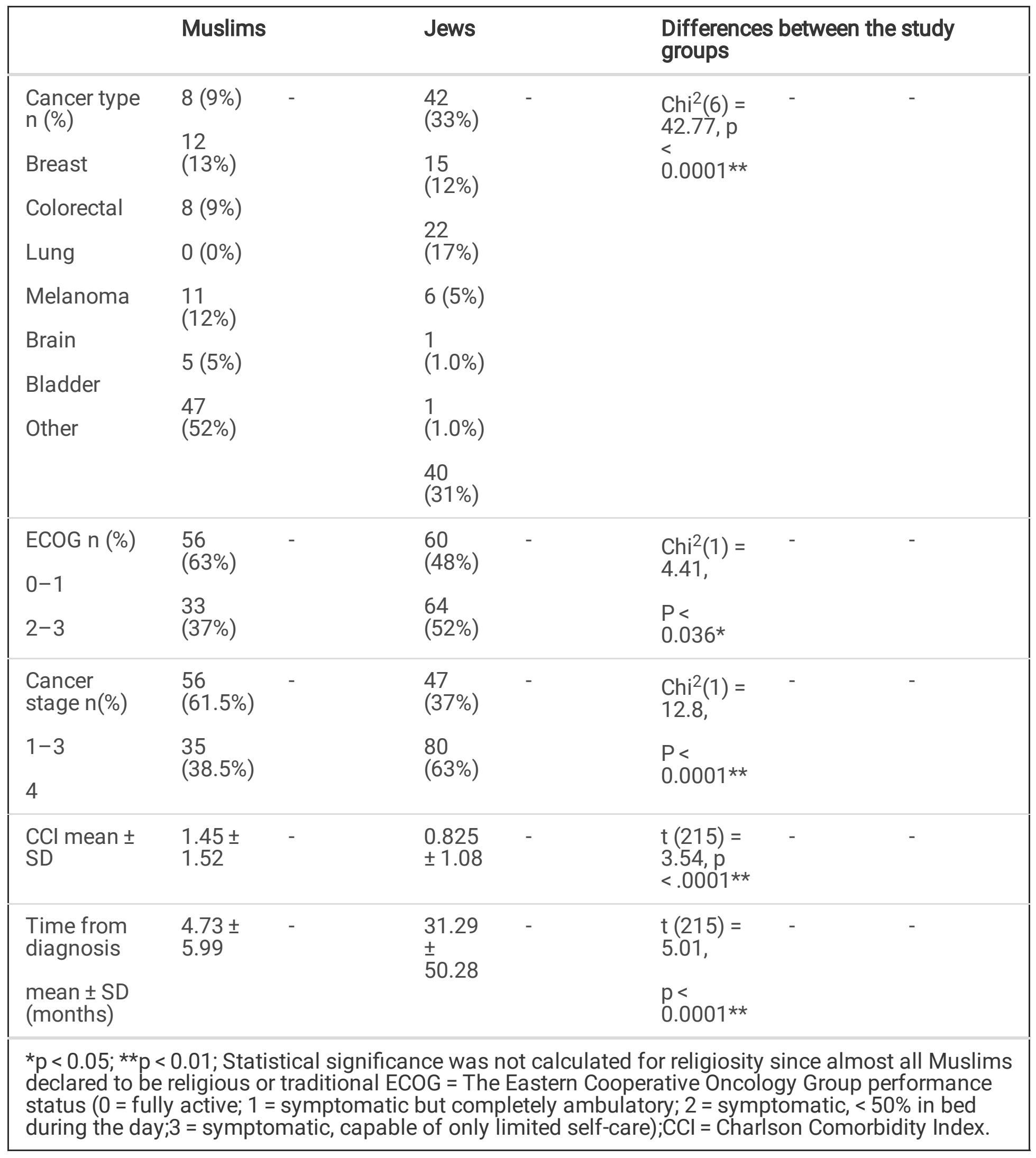

PATIENTS' MEDICAL DATA: Common cancer types in both samples were lung, colorectal, prostate and breast. Breast and lung cancers were more prevalent in the Jewish Israeli sample (33 and 17 percent, respectively, compared with 9 and 9 percent, respectively, for the Muslim Palestinians). The category 'other' included rare cancer types or patients with combinations of two or more synchronous cancers. 
In comparison with the Muslim Palestinian patients, the Jewish Israelis had significantly lower functional status, and more of them had metastatic cancers (63 percent compared with 38.5 percent of the Muslim Palestinian patients).

Mean time since diagnosis was significant -4.73 months for Muslim Palestinian patients and 31.82 months for the Jewish Israelis. It should be noted that 'time from diagnosis' was measured from the initial diagnosis at first presentation. In patients who had been treated, become 'disease-free' and then returned with advanced disease, 'time from diagnosis' did not include the time spent 'disease-free' - a period for which information could not be obtained.

\section{Ethical approval and procedure}

The study protocol was approved by the Medical Ethics Review Committees of the Hadassah-Hebrew University Medical Center, Chaim Sheba Medical Center, Assuta Ashdod University Hospital and the Makassed Hospital. All methods were carried out in accordance with relevant guidelines and regulations. Informed consent was obtained from all subjects and/or their legal guardian(s). With permission from the attending physicians, patients were approached

during routine medical visits to outpatient clinics or during chemotherapy sessions. Each participant signed an informed consent form. Data were collected between August 2014 and August 2020 (Jewish Israeli participants) and December 2019 and March 2020 (Muslim Palestinian participants).

\section{Measures}

BACKGROUND DATA: Sociodemographic data were collected directly from patients and caregivers. Data regarding the patients' diagnoses, treatment, cancer stage, Eastern Cooperative Oncology Group (ECOG) performance status and Charlson Comorbidity Index (CCI) [13] were obtained from the medical records.

DEPRESSION: Depression was measured using the five-item version of the Geriatric Depression Scale (5item GDS). This is a shorter form of the 15-item Geriatric Depression Scale, which has proven as effective as the longer validated version [14]. The scale consists of five binary items (for example, 'Are you basically satisfied with your life?') with each individual item scoring $0-1$, the five items thus scoring in a range of $0-5$. The English and Hebrew versions were reported valid and reliable as was the longer Arabic version [15]. For the current study, we used the five relevant items from the longer validated Hebrew version and a professional translation of the English version into Arabic, as required by the Helsinki Committee. The recommended cutoff score $\geq 2$ is the clinical cutoff for susceptibility to depression [16]. Reliability values (Standardized McDonald's Omega, Maximum likelihood) [17] were: Muslim Palestinian patients, 0.71; Muslim Palestinian caregivers, 0.72; Jewish Israeli patients, 0.82; Jewish Israeli caregivers, 0.56 .

PERCEIVED SOCIAL SUPPORT: Caregiver support was assessed using the Cancer Perceived Agents of Social Support [18], which is a 12-item questionnaire (for example, 'To what extent do you feel you receive helpful information from your spouse?'), each item scoring in a range of $1-5$. The scale combines two 
theoretical content facets of social support - agent of support and type of support. This study uses the aggregate score of the agents (spouse, family, friends, beliefs), each based on the mean of three types of support (instrumental, cognitive and emotional). The Hebrew version of the scale has been proven valid and reliable for Jewish Israeli patients and their spouses in Israel [18]. For the Muslim Palestinian sample, we used a professional translation of the Hebrew version into Arabic. Reliability values (Standardized McDonald's Omega, Maximum likelihood) were: Muslim Palestinian patients $=0.80,0.81,0.63$ and 0.81 (spouse, family, friends, beliefs, respectively); Muslim Palestinian caregivers $=0.70,0.76,0.63$ and 0.83 (spouse, family, friends, beliefs, respectively); Jewish Israeli patients $=0.78,0.82,0.885$ and 0.975 (spouse, family, friends, beliefs, respectively); Jewish Israeli caregivers $=0.87,0.86,0.89,0.96$ (spouse, family, friends, beliefs, respectively).

HOPE: Hope was assessed by the 1) Adult Hope Scale (AHS) [19] and by and 2) an additional six single items targeting specific hope content, 3 ) three time-dependent hope items.

The AHS is a 12-item measure (4-point Likert-type scale) comprising two components: agency (goaldirected determination) and pathways (routes to achieving goals). The AHS contains eight hope items and four fillers. For the Jewish sample, we used a Hebrew translation of the English version [20], and for the Muslim Palestinian sample a professional Arabic translation of the English version. Cronbach's alphas for the aggregate measure of the eight hope items were 0.85 for Muslim Palestinian patients and 0.895 Jewish Israeli patients.

The six single items, used for targeting specific hope content and measuring the extent to which patients hoped, were the hope of (1) staying alive; (2) being pain-free; (3) being with family; (4) being more active and less tired; (5) dying without pain; and (6) being cured. Each was rated on a Likert-type scale of 1-5. Reliability values (Standardized McDonald's Omega, Maximum likelihood) were 0.75 for Muslim Palestinian patients; 0.79 for Muslim Palestinian caregivers; 0.90 for Jewish Israeli patients; and 0.73 for

Jewish Israeli caregivers. The time dependent hope items: Analyses included three single items assessing hope, rated on a Likert-type scale of 1-5. Participants were asked to estimate their level of hope for the present, for a year from now, and for five years from now.

\section{Statistical analysis}

COMPARISONS BETWEEN THE STUDY GROUPS: A two-way MANOVA (ethnicity by role) was used to compare reported levels of depression, hope, single hope items and perceived social support between the study groups. Covariates controlled for background variables (age, education and number of people per household). Religiosity was also not included as a covariate since, as indicated, almost all the Muslim Palestinians declared themselves religious or traditional.

PREDICTING DEPRESSION: A separate regression model was calculated for each of the study groups. The predicted variable was depression, and the predictors were perceived social support, hope (AHS), single hope items and background variables. The medical variables of the patients were included, other 
than cancer type which had too many subcategories. Data were analyzed with IBM SPSS Statistics (Version 25) predictive and analytic software.

\section{Availability of Data and Materials}

The dataset analyzed during the current study are available in The Open Science Framework (OSF) at: https://doi.org/10.17605/OSF.IO/CK3T8

\section{Results}

\section{Comparison of study variables between ethnic and role groups}

Table 2 shows the comparison by two-way MANOVA (ethnicity by role) of depression, hope, single hope items and social support between the study groups, with age education and number of people per household as covariates 
Table 2

Study variables (estimated marginal means) by study groups.

\begin{tabular}{|c|c|c|c|c|c|c|c|}
\hline & \multicolumn{2}{|c|}{ Muslims } & \multicolumn{2}{|l|}{ Jews } & \multicolumn{3}{|c|}{$\begin{array}{l}\text { Differences between the study } \\
\text { groups }\end{array}$} \\
\hline & $\begin{array}{l}\text { Patient } \\
\mathrm{N}=91\end{array}$ & $\begin{array}{l}\text { Caregivers, } \\
\mathrm{N}=61\end{array}$ & $\begin{array}{l}\text { Patient, } \\
N=127\end{array}$ & $\begin{array}{l}\text { Caregivers, } \\
\mathrm{N}=214\end{array}$ & $\begin{array}{l}\text { Ethnicity } \\
\text { effect }\end{array}$ & $\begin{array}{l}\text { Role } \\
\text { effect }\end{array}$ & $\begin{array}{l}\text { Interaction } \\
\text { effect }\end{array}$ \\
\hline & $\begin{array}{l}\text { Mean } \\
\pm S E\end{array}$ & Mean \pm SE & $\begin{array}{l}\text { Mean } \\
\pm S E\end{array}$ & Mean \pm SE & $\begin{array}{l}F(1,457)= \\
; p<\end{array}$ & $\begin{array}{l}F(1,457)= \\
; p<\end{array}$ & $\begin{array}{l}F(1,457)=; \\
p<\end{array}$ \\
\hline Depression & $\begin{array}{l}3.11 \pm \\
0.15\end{array}$ & $3.38 \pm 0.17$ & $\begin{array}{l}1.66 \pm \\
0.11\end{array}$ & $0.99 \pm 0.09$ & $\begin{array}{l}153.94 ; \\
0.0001^{\star \star}\end{array}$ & $\begin{array}{l}2.31 ; \\
0.129 \\
\text { N.S }\end{array}$ & $\begin{array}{l}15.36 ; \\
0.0001 * \star\end{array}$ \\
\hline Hope & $\begin{array}{l}5.1 \pm \\
0.08\end{array}$ & $5.06 \pm 0.09$ & $\begin{array}{l}2.89 \pm \\
0.06\end{array}$ & $3.16 \pm 0.05$ & $\begin{array}{l}593.93 \\
0.0001 * \star\end{array}$ & $\begin{array}{l}2.82 ; \\
0.094 \\
\text { N.S }\end{array}$ & $\begin{array}{l}5.34 ; \\
0.021 *\end{array}$ \\
\hline Hope now & $\begin{array}{l}3.67 \pm \\
0.12\end{array}$ & $3.3 \pm 0.13$ & $\begin{array}{l}3.63 \pm \\
0.09\end{array}$ & $3.93 \pm 0.07$ & $\begin{array}{l}5.84 \\
0.002^{\star \star}\end{array}$ & $\begin{array}{l}0.12 ; \\
0.729 \\
\text { N.S }\end{array}$ & $\begin{array}{l}12.86 ; \\
0.0001 * \star\end{array}$ \\
\hline $\begin{array}{l}\text { Hope in } \\
\text { one year }\end{array}$ & $\begin{array}{l}3.4 \pm \\
0.11\end{array}$ & $2.98 \pm 0.13$ & $\begin{array}{l}3.76 \pm \\
0.09\end{array}$ & $3.99 \pm 0.07$ & $\begin{array}{l}33.81 ; \\
0.0001 * *\end{array}$ & $\begin{array}{l}0.99 ; \\
0.319 \\
\text { N.S }\end{array}$ & $\begin{array}{l}12.63 ; \\
0.0001 \star \star\end{array}$ \\
\hline $\begin{array}{l}\text { Hope in } \\
\text { five year }\end{array}$ & $\begin{array}{l}2.93 \pm \\
0.13\end{array}$ & $2.55 \pm 0.14$ & $\begin{array}{l}3.56 \pm \\
0.1\end{array}$ & $3.87 \pm 0.07$ & $\begin{array}{l}54.89 ; \\
0.0001 * \star\end{array}$ & $\begin{array}{l}0.08 ; \\
0.772 \\
\text { N.S }\end{array}$ & $\begin{array}{l}11.39 ; \\
0.0001^{* \star}\end{array}$ \\
\hline $\begin{array}{l}\text { Perceived } \\
\text { spouse } \\
\text { support }\end{array}$ & $\begin{array}{l}3.79 \pm \\
0.11\end{array}$ & $3.42 \pm 0.13$ & $\begin{array}{l}4.48 \pm \\
0.09\end{array}$ & $3.84 \pm 0.07$ & $\begin{array}{l}21.44 ; \\
0.0001 * \star\end{array}$ & $\begin{array}{l}25.29 ; \\
0.000 i^{*} * \star\end{array}$ & $\begin{array}{l}2.23 ; \\
0.136 \mathrm{~N} . \mathrm{S}\end{array}$ \\
\hline $\begin{array}{l}\text { Perceived } \\
\text { family } \\
\text { support }\end{array}$ & $\begin{array}{l}3.84 \pm \\
0.11\end{array}$ & $3.58 \pm 0.12$ & $\begin{array}{l}4.2 \pm \\
0.08\end{array}$ & $4.01 \pm 0.06$ & $\begin{array}{l}12.99 \\
0.0001 * \star\end{array}$ & $\begin{array}{l}6.02 ; \\
0.015^{*}\end{array}$ & $\begin{array}{l}0.17 ; \\
0.682 \text { N.S }\end{array}$ \\
\hline $\begin{array}{l}\text { Perceived } \\
\text { friends } \\
\text { support }\end{array}$ & $\begin{array}{l}2.98 \pm \\
0.14\end{array}$ & $2.6 \pm 0.15$ & $\begin{array}{l}3.4 \pm \\
0.1\end{array}$ & $3.29 \pm 0.08$ & $\begin{array}{l}15.4 ; \\
0.0001 * \star\end{array}$ & $\begin{array}{l}4.22 ; \\
0.04^{\star}\end{array}$ & $\begin{array}{l}1.58 ; 0.21 \\
\text { N.S }\end{array}$ \\
\hline $\begin{array}{l}\text { Perceived } \\
\text { faith } \\
\text { support }\end{array}$ & $\begin{array}{l}2.26 \pm \\
0.17\end{array}$ & $2.2 \pm 0.19$ & $\begin{array}{l}2.85 \pm \\
0.13\end{array}$ & $2.7 \pm 0.1$ & $\begin{array}{l}9.39 \\
0.002^{\star \star}\end{array}$ & $\begin{array}{l}0.48 ; \\
0.49 \text { N.S }\end{array}$ & $\begin{array}{l}0.13 ; 0.72 \\
\text { N.S }\end{array}$ \\
\hline
\end{tabular}

DEPRESSION: Significant interaction effect for depression was found in univariate analysis. Among the Muslim Palestinians, depression was higher in caregivers than in patients, whereas the reverse was true for the Jewish Israelis. Depression in the Muslim Palestinian groups was overall significantly higher than that among the Jewish Israeli groups. 
HOPE: Significant interaction effects were found for both the AHS and single hope items. In the Muslim Palestinian groups, hope was higher among patients than caregivers. As with depression, the reverse was true for the Jewish Israeli groups. Whereas the AHS was significantly higher among Muslim Palestinians in comparison with Jewish Israelis, however, single hope items were higher for the Jewish Israelis than the Muslim Palestinian groups.

Since there were several differences in medical data between the patients' groups, we re-examined the ethnic effect comparing the Jewish women to the Muslim women with age, education, number of persons in the household, ECOG, stage, $\mathrm{CCl}$ and time from diagnosis. The results were similar: Both depression and hope (AHS) were significantly higher among Muslims hope in 1 year and hope in 5 years were significantly higher among Jews, spouse, family and friends support were higher among the Jewish women. Hope now and faith support did not differ significantly between the groups.

\section{Simple correlation to depression}

Table 3 presents the zero-order correlation between the study variables and depression by study group. 
Table 3

Simple correlation between depression and study variables by study groups data by study groups.

\begin{tabular}{|c|c|c|c|c|}
\hline & $\begin{array}{l}\text { Muslim } \\
\text { patients }\end{array}$ & $\begin{array}{l}\text { Muslim } \\
\text { caregivers }\end{array}$ & $\begin{array}{l}\text { Jewish } \\
\text { patients }\end{array}$ & $\begin{array}{l}\text { Jewish } \\
\text { caregivers }\end{array}$ \\
\hline Age & 0.08 N.S & 0.15 N.S & $0.70^{\star \star}$ & -0.07 N.S \\
\hline Education & -0.14 N.S & $-0.34^{\star *}$ & $-0.475^{* *}$ & -0.02 N.S \\
\hline \multicolumn{5}{|l|}{$0=$ Under 9 years; $1=9$ years and above } \\
\hline number of people in house & 0.11 N.S & 0.001 N.S & 0.17 N.S & -0.03 N.S \\
\hline Hope (AHS) & -0.28 ** & $-0.30^{*}$ & $-0.77^{\star \star}$ & $-0.25^{\star \star}$ \\
\hline hope now & -0.195 N.S & -0.15 N.S & $-0.61^{\star \star}$ & $-0.20^{\star \star}$ \\
\hline hope in 1year & $-0.225^{*}$ & -0.11 N.S & $-0.58^{\star *}$ & $-0.26^{* *}$ \\
\hline hope in 5years & $-0.31^{\star \star}$ & -0.03 N.S & $-.59^{\star \star}$ & $-0.18^{* *}$ \\
\hline Perceived spouse support & -0.10 N.S & $-0.29^{*}$ & -0.12 N.S & $-0.395^{\star *}$ \\
\hline Perceived family support & $-0.255^{\star}$ & -0.17 N.S & -0.16 N.S & $-0.23^{* *}$ \\
\hline Perceived friends support & $-0.28^{\star *}$ & -0.22 N.S & $-0.41^{* \star}$ & $-0.27^{\star \star}$ \\
\hline Perceived faith support & $-0.24^{*}$ & 0.01 N.S & $-0.102 \mathrm{NS}$ & 0.006 N.S \\
\hline Time from diagnosis & -0.03 N.S & - & $-0.19^{*}$ & - \\
\hline Functional status & -0.05 N.S & - & $0.38^{\star \star}$ & - \\
\hline \multicolumn{5}{|l|}{$\begin{array}{l}0=\text { No or low levels symptoms } 1=\text { high } \\
\text { level symptoms }\end{array}$} \\
\hline Stage $0=$ non metastatic $1=$ metastatic & 0.1 N.S & - & 0.01 N.S & - \\
\hline $\begin{array}{l}\text { Comorbidities (Charlson Comorbidity } \\
\text { Index) }\end{array}$ & 0.12 N.S & - & $0.42^{\star \star}$ & - \\
\hline
\end{tabular}

MUSLIM PALESTINIAN PATIENTS: Depression was negatively related to the following variables: hope (AHS, $p<0.01)$, hope in one year $(p<0.05)$, hope in five years $(p<0.01)$, perceived family support $(p<$ $0.05)$, perceived friend support $(p<0.01)$ and perceived faith support $(p<0.05)$. None of the medical variables was found to correlate with depression in this group.

MUSLIM PALESTINIAN CAREGIVERS: Depression was negatively related to the following variables: education $(p<0.001)$, hope $(A H S, p<0.05)$ and perceived spousal support $(p<0.05)$. 
JEWISH ISRAELI PATIENTS: Older age $(p<0.01)$, lower functional status, shorter time from diagnosis and more comorbidities $(p<0.01)$ were all found to correlate significantly with greater levels depression.

Higher education and greater hope (all hope variables - AHS and single hope items) correlated with lower levels of depression. Depression was negatively related to the following variables, higher levels of depression correlating with lower levels of these variables: education $(p<0.01)$, higher functional status $(p<0.01)$, time from diagnosis $(p<0.05)$ and all hope items, including AHS and support from friends $(p<$ $0.01)$.

JEWISH ISRAELI CAREGIVERS: Depression was negatively related to the following variables, with higher levels of depression correlating with lower levels of these variables: all hope items including AHS $(p<$ $0.01)$ and all perceived support items other than perceived faith support $(p<0.01)$.

The sole variable that related to depression in all groups was the AHS, with higher levels correlated with lower levels of depression.

\section{Predicting depression}

Caregiver models included age, education, hope (AHS), single hope items and social support. Number of people per household was excluded from the regression since it did not significantly correlate to depression in any group. Patient models included comorbidities, time since diagnosis and functional status. Disease stage did not significantly relate to depression in any group and was excluded.

MUSLIM PALESTINIAN PATIENTS: The regression model was found to be significant. Adjusted R2 $=0.16$, $F(12,76)=2.38, p<0.011$. The only significant predictors of depression were education and perceived faith support. Higher levels of both variables were related to lower levels of depression.

MUSLIM PALESTINIAN CAREGIVERS: The regression model was not significant. Adjusted R2 $=0.048$, $F(10,50)=1.32, p<0.26$. A post hoc stepwise analysis revealed that the only significant predictor was education, higher levels of which related to lower levels of depression.

JEWISH ISRAELI PATIENTS: The regression model was found to be significant. Adjusted R2 $=0.6$, $F(12,109)=16.91, p<0.0001$. The only significant predictor of depression was hope (AHS). Higher levels of hope were related to lower levels of depression.

JEWISH ISRAELI CAREGIVERS: The regression model was found to be significant. Adjusted R2 $=0.18$, $F(10,199)=5.67, p<0.0001$. The significant predictors of depression were hope (AHS), hope in one year and spousal support, higher levels of which were related to lower levels of depression.

\section{Discussion}

Our study compared psychological responses to cancer among older Muslim Palestinian and Jewish Israeli women treated in the Jerusalem area- both among older women diagnosed with cancer as well as those who are informal spousal caregivers to older men with cancer. It aimed to understand 
psychological variables (hope, support and perceived social support) and the psycho-cultural complexity of cancer among Muslim and Jewish women.

Statistical analyses indicate a sharp and significant difference in the responses of Muslim Palestinian and Jewish Israeli women to cancer. Depression was more prevalent among the former, whose perceived support from spouse, family and friends was significantly lower. Lowest levels of perceived support were reported among Muslim woman who were informal spousal caregivers. Similar levels of depression were found among Muslim patients and caregivers, in contrast to Jewish Israeli women, where prevalence of depression was significantly lower among caregivers (Fig. 1).

It is of course both necessary and important at the outset of this discussion, to acknowledge the specific geo-political background against which these findings are framed, recognizing existing socioeconomic and educational disparities. As regards access to health care, a recent review of cancer care within the Palestinian Healthcare system noted that while overall health care is actually one of the best among Arab countries, nonetheless palliative care is extremely sparse, and still remains an emerging specialty, lacking a formal organized program [21,22]. Despite this important caveat, it nonetheless is plausible that divergent conceptions, as well as possible misconceptions, of cancer within the Muslim and Jewish groups included in this study result from a combination of their different traditions, languages and health perceptions. Identifying the psychological and cultural disparities engendered by family cultures and belief systems may account for contrasts in coping with cancer and cancer outcomes. It may also give healthcare practitioners better understanding of the perception of roles among older women as patients and caregivers in Muslim and Jewish societies [23], as well as guide them in using cultural and spiritual traditions as tools for change and empowerment.

One major disparity between the two samples is the social-cultural milieu. Muslim Palestinian women live in a more traditionally collectivist society, which prioritizes the needs and goals of family over those of the single individual. Unlike the Jewish Israeli family unit, the Palestinian Muslim family (which encompasses grandparents, grandchildren, aunts and uncles in an extended grouping) is central to the identity of its members, and the source of its physical, material and social support and decision-making [24]. The traditional role of women within this unit is to provide emotional and practical support, and preserve family values and cultural norms. This can make the cancer-triggered transformation, from caretaker to care recipient, a particularly challenging transition accompanied by potential feelings of vulnerability, loss of status and shame [25, 26]. Guilt, uncertainty and fear are common responses [27], and despite their large, extended family, Muslim Palestinian women in this study felt less supported by spouse, family and friends than the Jewish Israeli women for whom there are fewer cultural connotations of shame or guilt concerning their illness (Tables 1, 2).

Furthermore, there remains a strong taboo associated with cancer among Muslim Palestinians, an illness which is commonly perceive as irrevocably terminal by nature [28-31]. Among Arab women in both Israel and the Gaza Strip, studies have reported breast cancer patients making extreme efforts to hide their illness to the point of eschewing public gatherings and celebrations $[28,3]$. 
Jewish Israelis typically do not hide their illness, in general believing in individual and partnership autonomy in making their medical and healthcare decisions. Jewish Israeli women commonly share and consult with their small nuclear families and have been shown to display a high degree of trust concerning available medical resources [33]. They seek information and relate to the medical-nursing staff as partners through the critical process of diagnosis, treatment and rehabilitation [34, 35]. While the Jewish Israelis expect full information about their condition and participate in their medical and healthcare decisions, the Muslim patients are generally shielded from this by their families, who make their medical decisions for them.

The relatively lower prevalence of depression among the Jewish Israeli caregivers in our study was an unexpected finding. It might be suggested that perhaps the significant protective factor is their ability to derive meaning from the caregiving process, something which may be less available to the Muslim Palestinian women, whose perception of the illness as fatal and taboo, was also accompanied by their heavier socio-economic burden. In a previous study, we reported [36] high levels of hope in caregivers, seeing this as possibly a form of adaptive coping rather than withdrawal. In terms of Snyder's definition of hope $[19,37]$, it may be assumed that caregivers facing a distressed patient may adjust their goals toward those which are achievable and meaningful. On the other hand, this gap between patients and caregivers was not seen in the Muslim group. We hypothesize that the powerful negative stigma that accompanies cancer for Muslim [12, 29-31,38] mitigates their ability to adjust toward achievable and meaningful goals. Further, the burden of care in this society is focused on informal caregivers - partners, children and other family members - rather than on formal caregivers.

\section{Study limitations}

One limitation of this study was lack of detailed data regarding specific systemic treatments, their results and expected prognosis, which may mediate perceived prognosis, depression and hope. It was also difficult to establish causality due to our study's cross-sectional template, as well as to identify longitudinal changes over time. External validation of our results to other populations is another limitation. While care of elderly Muslim Palestinians with cancer continues to be characterized by classical Muslim social culture (Table 1), nonetheless the society is in rapid cultural transition, with increasing secularization [39]. An additional limitation to consider is the possible influence of socioeconomic and educational differences between the groups on our findings.

\section{Implications for practice and policy}

Addressing the impact of a cancer diagnosis on older women, whether patients or caregivers, demands accurate assessment and understanding of their cultural milieu, and its complex interplay of psychological, religious and social factors. The psychological responses of depression and hope in the women in our study, as well as their perceptions of social support from family, friends and faith, were all strongly culturally determined. While our sample of Muslim Palestinians may not be representative of women in large and diverse Muslim populations of other regions, there are clear cultural similarities. The 
importance of our findings lies in its call to give greater attention to the potentially unmet psychological and social needs of older Muslim women confronting cancer as patients and caregivers, as well indeed as women across a range of other diverse cultures. Within the microcosm of our study population, Muslims and Jews, Palestinians and Israelis are living in societies in transition, which are bearing witness to rapid change. In time, despite the Middle East's geopolitical complexity, it is likely that increasing educational opportunities and shifting gender roles within traditional cultures will influence the psychological responses and dynamics described in our study. Our study highlights today's need to be proactive in identifying and addressing depression; understanding and incorporating hope into the therapeutic context; and, perhaps most importantly, attempt to understand the low levels of perceived social support reported by Muslim Palestinian women in our study [12, 22].

\section{Conclusions}

This exploratory study found significant differences in the psychological responses between older Muslim Palestinian and Jewish Israeli women confronting cancer, both as patients and as spousal caregivers. Our principle findings were the higher levels of depression and lower perceived social support, despite higher levels of hope which were experienced by Muslim Palestinian women. Whilst clearly limited to the local population included in our study, nonetheless our findings are a novel contribution to the psycho-oncology literature among older women as patients or caregivers of cancer patients. Among Muslim women confronting cancer in general, and older women in particular, current research is very sparse. While great caution must be exercised in drawing conclusions to different populations of Muslim women, nonetheless our findings do shed light on common areas which might benefit from further research, among Muslim women in both Muslim majority and minority countries.

Only then will it be possible to accurately develop an effective, culturally sensitive, and focused approach to cancer care, enabling pragmatic intervention by healthcare professionals.

\section{Abbreviations}

None

\section{Declarations}

Ethics approval and consent to participate - the study protocol was approved by the Medical Ethics Review Committees of the Hadassah-Hebrew University Medical Center, Chaim Sheba Medical Center, Assuta Ashdod University Hospital and the Makassed Hospital.

Consent for publication - not applicable

Availability of data and material - datasets generated and/or analysed during the current study are not publicly available due to Medical Ethics Review Committees study's approval. Yet, anonymous data are available from the corresponding author on reasonable request. 
Competing interest - not applicable.

Funding - this study was supported by Israel Cancer Association.

Authors' contributions

Study concept and design: YR, LB, JMJ, ES, GG.

Data acquisition and analyses: YR, LB, IMG, GG.

Drafting and approval of the manuscript: YR, LB, JMJ, IMG, ES, GG.

Acknowledgements - Not applicable

\section{References}

1. Anderson BO, llbawi AM, El Saghir NS. Breast cancer in low and middle income countries (LMICs): a shifting tide in global health. Breast J. 2015;21(1):111-8.

2. Ferlay JI, Soerjomataram M, Ervik R, et al. GLOBOCAN 2012 v1.0: Cancer Incidence and Mortality Worldwide: IARC CancerBase11." International Agency for Research on Cancer. Accessed November 9, 2021. https://publications.iarc.fr/Databases/larc-Cancerbases/GLOBOCAN-2012-EstimatedCancer-Incidence-Mortality-And-Prevalence-Worldwide-In-2012-V1.0-2012

3. Khorasani S, Rezaei S, Rashidian H, Daroudi R. Years of potential life lost and productivity costs due to premature cancer-related mortality in Iran. Asian Pac J Cancer Prev. 2015;16(5):1845-50.

4. Okonji D, Li D, VanderWalde N, Winer A, Williams GR, Arora SP. Geriatric oncology research presented at the ASCO GI 2020 symposium: Young international society of geriatric oncology perspective paper. J Geriatr Oncol. 2020;11(7):1182-1186.

5. Bray F, Jemal A, Grey N, Ferlay J, Forman D. Global cancer transitions according to the Human Development Index (2008-2030): a population-based study. Lancet Oncol. 2012;13(8):790-801.

6. Kagawa-Singer M, Dadia AV, Yu MC, Surbone A. Cancer, culture, and health disparities: time to chart a new course? CA Cancer J Clin. 2010;60(1):12-39.

7. Akram K, Abu Seir YR. Cancer Care in Palestine. In Cancer Care in Countries and Societies in Transition, edited by M. Silbermann, 2016;77-97.

8. DiFonzo N, Robinson NM, Suls JM, Rini C. Rumors about cancer: content, sources, coping, transmission, and belief. J Health Commun. 2012;17(9):1099-115.

9. El Hayek S, Dakroub A, Beaini H, Salem H, Saliba AN, Ehlers SL, Bizri M, Taher A. Psycho-oncology in the Arab world: The time is now. Psychooncology. 2022;31(1):148-151.

10. Goldzweig G, Baider L, Rottenberg Y, Andritsch E, Jacobs JM. Is age a risk factor for depression among the oldest old with cancer? J Geriatr Oncol. 2018;9(5):476-481. 
11. Goldzweig G, Schapira L, Baider L, Jacobs JM, Andritsch E, Rottenberg Y. Who will care for the caregiver? Distress and depression among spousal caregivers of older patients undergoing treatment for cancer. Support Care Cancer. 2019;27(11):4221-4227.

12. Charlson ME, Pompei P, Ales KL, MacKenzie CR. A new method of classifying prognostic comorbidity in longitudinal studies: development and validation. J Chronic Dis. 1987;40(5):373-83.

13. Weeks SK, McGann PE, Michaels TK, Penninx BW. Comparing various short-form Geriatric Depression Scales leads to the GDS-5/15. J Nurs Scholarsh. 2003;35(2):133-7.

14. Hassankhani H, Eghtedar S, Rahmani A, Ebrahimi H, Whitehead B. A Qualitative Study on Cancer Care Burden: Experiences of Iranian Family Caregivers. Holist Nurs Pract. 2019;33(1):17-26.

15. Hoyl MT, Alessi CA, Harker JO, Josephson KR, Pietruszka FM, Koelfgen M, Mervis JR, Fitten LJ, Rubenstein LZ. Development and testing of a five-item version of the Geriatric Depression Scale. J Am Geriatr Soc. 1999;47(7):873-8.

16. 17.

17. Goldzweig G, Hasson-Ohayon I, Meirovitz A, Braun M, Hubert A, Baider L. Agents of support: psychometric properties of the Cancer Perceived Agents of Social Support (CPASS) questionnaire. Psychooncology. 2010;19(11):1179-86.

18. Snyder CR, Harris C, Anderson JR, Holleran SA, Irving LM, Sigmon ST, Yoshinobu L, Gibb J, Langelle C, Harney P. The will and the ways: development and validation of an individual-differences measure of hope. J Pers Soc Psychol. 1991;60(4):570-85.

19. Drach-Zahavy A. Difficult Goals: A Challenge or a Threat? The Effects of Situational Conditions: Goal Setting and Stress, and Personal Disposition. Technion Israel Institute of Technology, Haifa, Israel. Accessed November 9, 2021. https://iew3.technion.ac.il/ merez/papers/dz.pdf

20. Abu-Rmeileh NME, Gianicolo EAL, Bruni A, Mitwali S, Portaluri M, Bitar J, Hamad M, Giacaman R, Vigotti MA. Cancer mortality in the West Bank, Occupied Palestinian Territory. BMC Public Health. 2016;26:16:76.

21. Halahleh K, Gale RP. Cancer care in the Palestinian territories. Lancet Oncol. 2018;19(7):e359-e364.

22. Albarghouthi SI, Klempe SH. Al-Khabith-The malignant Cunning Disease: Sociocultural Complexity and Social Representations of Cancer in the Occupied Palestinian Territory." Culture \& Psychology 2019;25(1):99-131.

23. Almuhtaseb MI, Alby F, Zucchermaglio C, Fatigante M. Religiosity as a Cultural Resource for ArabPalestinian Women's Coping with Cancer. SAGE Open 2020;10(1):2158244019898730.

24. Azaiza F. Processes of Conservation and Change in Arab Society in Israel: Implications for the Health and Welfare of the Arab Population. International Journal of Social Welfare 2013;22(1):15-24.

25. Sinunu M, Yount KM, El Afify NA. Informal and formal long-term care for frail older adults in Cairo, Egypt: family caregiving decisions in a context of social change. J Cross Cult Gerontol. 2009;24(1):63-76. 
26. Doumit MA, Huijer HA, Kelley JH, El Saghir N, Nassar N. Coping with breast cancer: a phenomenological study. Cancer Nurs. 2010;33(2):E33-9.

27. Ishami M, Bottcher B, Alkhatib M, Ismail I, Abu-Nemer K, Hana M, Qandeel A, Abdelwahed A, Yazji H, Abuamro H, Matar G, Alsahhar A, Abolamzi A, Baraka O, Elblbessy M, Samra T, Alshorbassi N, Elshami A. Perceived barriers to seeking cancer care in the Gaza Strip: a cross-sectional study. BMC Health Serv Res. 2021;21(1):28.

28. Hammoudeh W, Hogan D, Giacaman R. From a Death Sentence to a Disrupted Life: Palestinian Women's Experiences and Coping With Breast Cancer. Qual Health Res. 2017;27(4):487-96.

29. Hwang J. Factors Influencing Breast Cancer Screening Practices among Arabic Women Living in the State of Qatar. Master's diss., University of Calgary, 2013. Accessed January 18, 2022. https://prism.ucalgary.ca/handle/11023/814.

30. Lamyian M, Hydarnia A, Ahmadi F, Faghihzadeh S, Aguilar-Vafaie ME. Barriers to and factors facilitating breast cancer screening among Iranian women: a qualitative study. East Mediterr Health J. 2007;13(5):1160-9.

31. Goldblatt H, Cohen M, Azaiza F, Manassa R. Being within or being between? The cultural context of Arab women's experience of coping with breast cancer in Israel. Psychooncology. 2013;22(4):86975.

32. Kadmon I, Kislev L. Israeli breast care nurses as a learning organization. Asia Pac J Oncol Nurs. 2015;2(1):3-7.

33. Kadmon I, Halag H, Dinur I, Katz A, Zohar H, Damari M, Cohen M, Levin E, Kislev L. Perceptions of Israeli women with breast cancer regarding the role of the Breast Care Nurse throughout all stages of treatment: a multi center study. Eur J Oncol Nurs. 2015;19(1):38-43.

34. Admi H, Zohar H, Rudner Y. "Lighthouse in the dark": a qualitative study of the role of breast care nurse specialists in Israel. Nurs Health Sci. 2011;13(4):507-13.

35. Goldzweig G, Baider L, Andritsch E, Rottenberg Y. Hope and social support in elderly patients with cancer and their partners: an actor-partner interdependence model. Future Oncol. 2016;12(24):28019.

36. Gum A, Snyder CR. Coping with terminal illness: the role of hopeful thinking. J Palliat Med. 2002;5(6):883-94.

37. Baider L, Goldzweig G, Jacobs JM, Ghrayeb IM, Sapir E, Rottenberg Y. Informal caregivers of older Muslims diagnosed with cancer: A portrait of depression, social support, and faith. Palliat Support Care. 2021;19(5):598-604.

38. Abdelmoneium AO, Alharahsheh ST. Family Home Caregivers for Old Persons in the Arab Region: Perceived Challenges and Policy Implications. Open Journal of Social Sciences 2016;4(1):151-64.

39. Dallmayr F. Radical Changes In The Muslim World: Turkey, Iran, Egypt. Philosophy \& Social Criticism 2012;38(4-5):497-506.

\section{Figures}




\section{HOPE AND DEPRESSION}
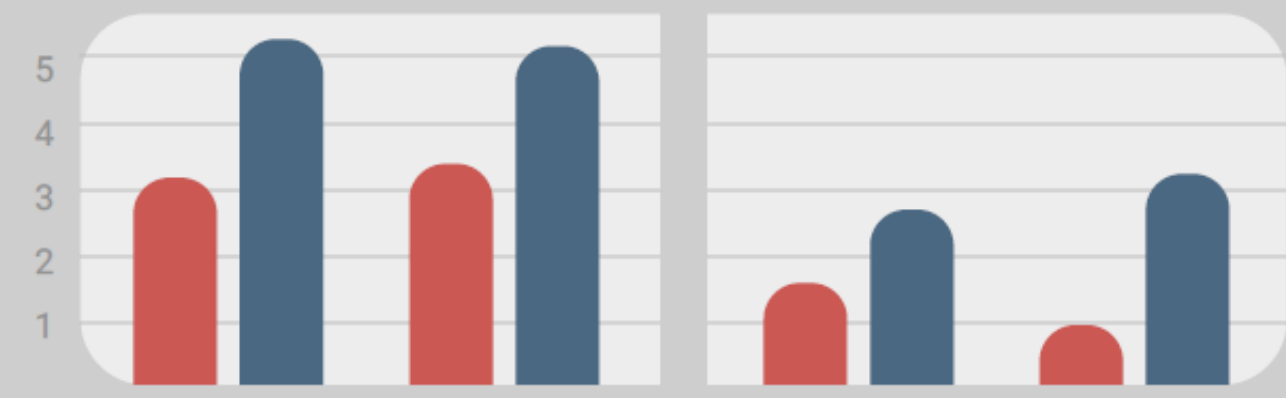

Depression

Hope

Patient

Caregivers

Patient

Caregivers

Muslims

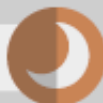

Jews

\section{HOUSHOLD AND PERCIEVED family \& friends support}

Number of persons in household

Perceived family support

Perceived friends support

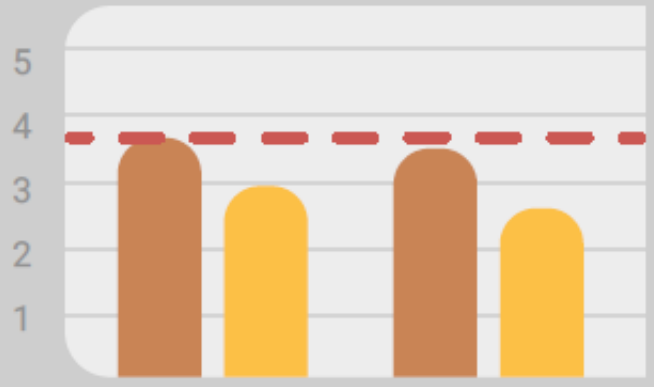

Patient
Caregivers

Muslims

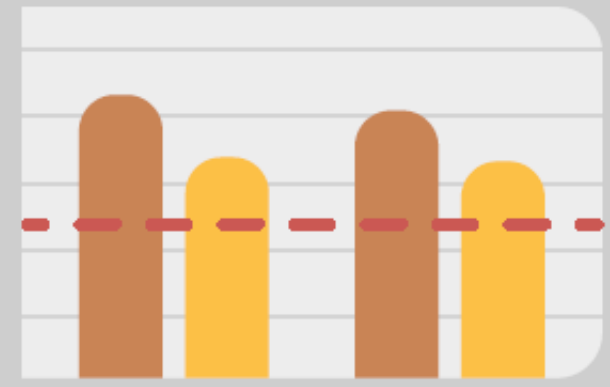

Patient
Caregivers

Jews

Figure 1

summarize of the main study's results 